\title{
The study of the stability of motion of the modular machine-tractor assembly
}

\author{
Bulgakov V. ${ }^{1}$, Nadykto V. ${ }^{2}$, Holovach I. ${ }^{3}$, Prysiazhniuk D. ${ }^{4}$, Parakhin $0 .{ }^{5}$ \\ ${ }^{1,3}$ National University of Life and Environmental Sciences of Ukraine \\ 15 Heroiv Oborony Str., Kyiv, 03041, Ukraine \\ 2, 5 Tavria State Agrotechnological University named after Dmytro Motornyi \\ 18 B. Khmelnytskoho Ave., Melitopol, Zaporizhzhia oblast, 72312, Ukraine, ${ }^{4}$ Ladyzhynskyi College of \\ Vinnytsia National Agrarian University \\ 5 P. Kravchyka Str., Ladyzhyn, Vinnytsia oblast, 24321, Ukraine \\ e-mail: 1vbulgakov@meta.ua, ${ }^{2}$ volodymyr.nadykto@tsatu.edu.ua, ${ }^{3}$ holovach.iv@gmail.com, \\ 4m09049@meta.ua, 5oleksandr.parakhin@tsatu.edu.ua \\ ORCID: ${ }^{10000-0003-3445-3721, ~}{ }^{20000-0002-1770-8297, ~}{ }^{3} 0000-0003-1387-4789,{ }^{4} 0000-0002-6369-$ \\ $5781,{ }^{5} 0000-0003-1972-3762$
}

Goal. To explore theoretically and experimentally the increase of stability of the pivot connection of the technological and power modules of a new design of the modular machine-tractor unit. Methods. Theoretical studies were carried out using the main provisions of the higher mathematics, theoretical mechanics, theory of automatic control. Experimental studies were carried out in field conditions on a real modular machine-tractor unit. Results. The new construction of the pivot connection of the technological module with the power module (tractor) of the modular machine-tractor unit is developed. To ensure satisfactory maneuverability of technological module when cornering it is equipped with vertical and horizontal joints. Limitation of turning ability of technological module relative to the power one in the horizontal plane through this vertical hinge is provided by a hydraulic cylinder, which over- and underpiston cavities are connected through a restrictor with the coefficient of hydraulic resistance at the level of $1.03 \times 106 \mathrm{~N} \cdot \mathrm{m} \cdot \mathrm{s} \cdot \mathrm{rad}-1$. Based on the equivalent power circuit, a mathematical model was created of movement of the unit, allowing to investigate theoretically its stability. As the energizing impact was taken the turning moment, created by external forces. Output parameters of the model were the angle of rotation of the technological module relative to the energy in the horizontal plane, and the heading angle of the latter. The theoretical study is confirmed experimentally. Conclusions. As a result of mathematical modeling, the change of speed of the unit from 2 to $5 \mathrm{~m} \cdot \mathrm{s}-1$ does not lead to a deterioration of the stability of motion, neither technological nor, especially, the power modules. The values of the coefficients of resistance of the introduction of wheel tires of power module do not affect its development of fluctuations of the energizing moment. However, the value of the coefficient of resistance of the introduction of the tire of each wheel of the technological module of modular traction vehicle should be not less than $160 \mathrm{kN} \cdot \mathrm{rad}-1$.

Key words: technological module, power module, differential equation, amplitude-frequency characteristics, phase-frequency characteristics.

DOI: https://doi.org/10.31073/agrovisnyk202005-08

One way to increase the productivity of machine and tractor units is to increase the power of the tractor engine. But the higher the engine power, the more problematic its implementation through the tractor's pulling power. This is especially acute when its energy saturation is more than $15 \mathrm{~kW} \cdot$ tons $^{-1}$.

A perspective direction of effective application of high level tractors of energy intensity is their construction as a modular traction device. In this case the traction device consists of two modules: energy and technological (Fig. 1). As the energy module a wheeled tractor is used, which has a synchronous PTO shaft. The technological module is an additional bridge with wheel drive from the synchronous PTO shaft of the energy module, that is, from a wheeled tractor.

To ensure satisfactory maneuverability of the modular traction device when driving in a curve (on the turning lanes or at transport crossings) its technological module is equipped with vertical and horizontal hinges. Vertical hinge provides rotation of the technological module of the energy module into angles $\pm 30^{\circ}$ on the horizontal plane, and the horizontal hinge on the angles $\pm 15^{\circ}$ on the transversal-vertical plane. 


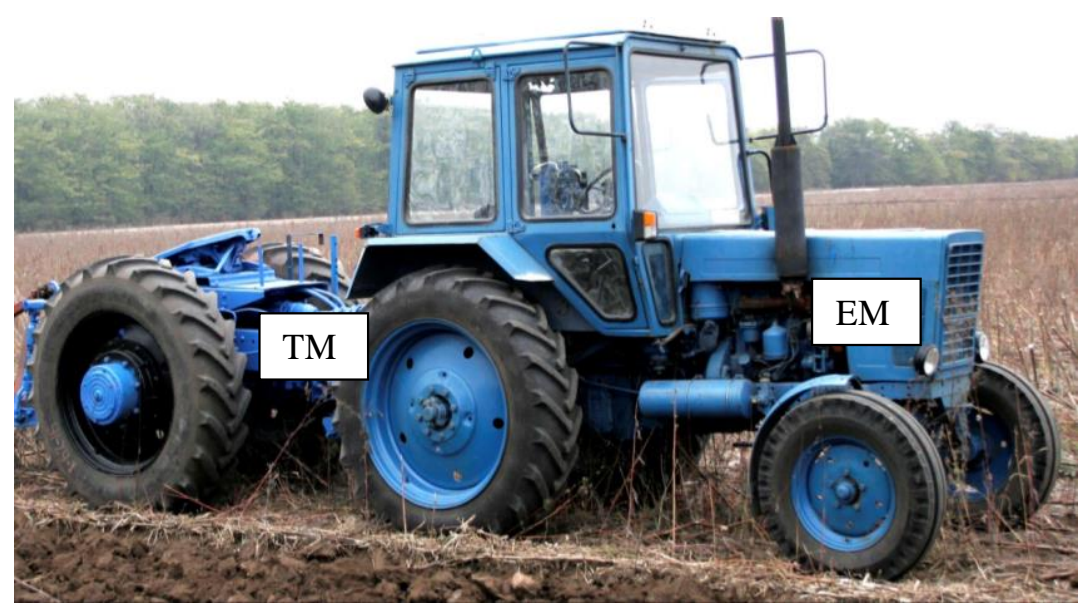

Fig. 1. Modular machine and tractor unit: EM - energy module; TM - technological module

In this case, the return limits of the technological module on the energy module in the horizontal plane through the above vertical hinge is provided by a hydraulic cylinder, which piston and piston cavity are connected to each other.

In addition, in the process of moving the modular traction device from one field to another, the technological module together with the agricultural machine targeting it can perform forced vibrations on the energy module. Quite often, the amplitude of these vibrations leads to a decrease in the stability of the technological module in the horizontal plane. As a result, there is a need to reduce the speed of the entire unit, and this affects the efficiency of working time and leads to a reduction in the performance of technological processes specified by the unit is an undesirable factor. Therefore, increasing the stability of motion of the modular machine and tractor unit is an urgent scientific and technical problem.

Analysis of recent research and publications. In the literature quite a lot of attention is paid to the question of stability of movement of hinged-connected energy devices [1-11].

But results of researches received earlier are not absolutely suitable for elimination of a problem considered by us. It should be noted at once that the direction of our research is due to the scientific hypothesis, the essence of which is the following: "It is possible to increase the stability of transport movement of the unit on the basis of the modular traction device by damping the horizontal vibrations of the technological module on the energy module by introducing a hydraulic damper between them". As a hydraulic damper a throttle can be used which connects the overpiston and underpiston cavity of the hydraulic cylinder and has a coefficient of resistance $1,03 \times 10^{6} \mathrm{H} \cdot \mathrm{m} \cdot \mathrm{s} \cdot \mathrm{rad}^{-1}[3]$.

In this article the results of theoretical and experimental research of stability of transport movement of the modular unit at change of speed of its movement, and also change of resistance coefficient to introduction of wheels tires of the technological module which hydraulic cylinder is equipped by a throttle with the specified above coefficient of hydraulic resistance are resulted.

Research objective. Increase of movement stability of the modular machine-tractor unit by development of a new construction of hinged connection of the technological module with power and theoretical and experimental researches of the specified stability.

Materials and methods. Theoretical research was carried out using the basic principles of higher mathematics, theoretical mechanics, the theory of automatic control. Experimental studies were conducted in the field on a real modular machine-tractor unit to confirm the theoretical results. Numerical calculations and graphical dependencies obtained using a PC based on developed and standard programs.

Results of the research. Assume that the modular unit, together with the YOX plane, performs planeparallel motion at a constant speed $V_{\circ}$ (Fig. 2). The practice of using many agricultural units shows that the assumption of the stability of their working speed is quite correct [12-13].. 


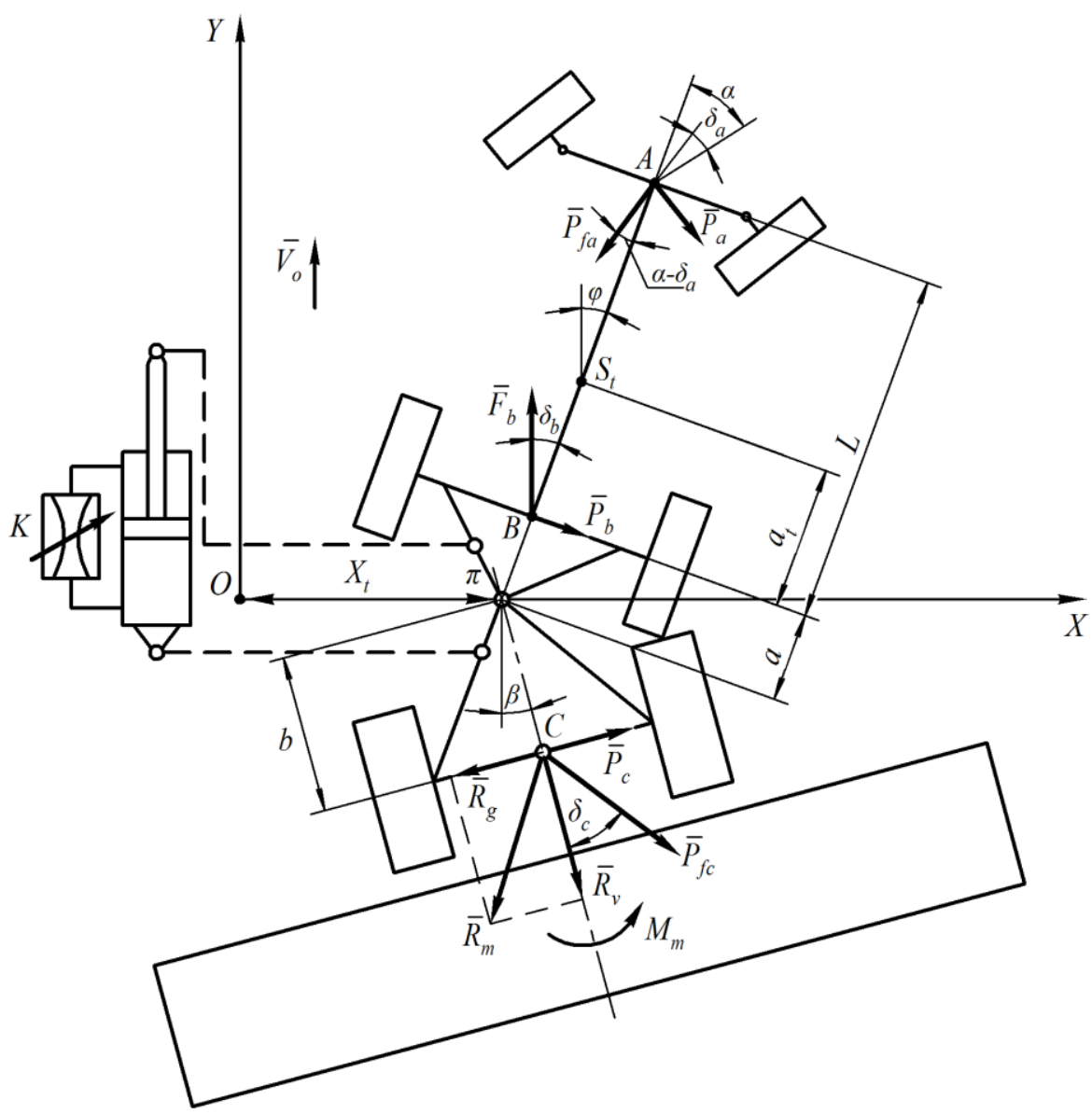

Fig. 2. An equivalent scheme of a modular machine-tractor unit

The position of the vertical hinge of the technological module, the axis of which passes through the point $\pi$, which is a reduced center of mass of the modular traction means, in the YOX plane is determined by the coordinate along the axis $\mathrm{OX}$.

In the YOX plane, the unit based on a modular towing vehicle has three degrees of freedom in form: transverse shift $X_{t}$ point $\pi$; course angle $\varphi$ of the energy module; angle $\beta$ - deviation of the technological module from the longitudinal axis of symmetry of the energy module.

In transport mode of movement of the unit on the basis of the modular traction device for its movement one developing rear axle of the power module of traction force is enough $F_{b}$ (Fig. 2). In addition to it, the modular unit is affected by: the forces of resistance to the front axle of the energy module $P_{f a}$ and bridge technology module $P_{f c}$; lateral forces $P_{a}, P_{b}$ and $P_{c}$, attached in points $A, B$ and $C$ in accordance; the main moment $M_{m}$ and the main vector $R_{m}$ external disturbance forces. The latter, in this case, is represented by its longitudinal $R_{v}$ and transverse $R_{g}$ compound.

The tires of the front and rear axle of the power module, and also the bridge of the technological module are removed by angles $\delta_{a}, \delta_{b}$ and $\delta_{c}$ in accordance.

As we have already noted, the mutual angular mobility of the technological module in the energy module in the horizontal plane is limited by a hydraulic cylinder, which overpiston and underpiston cavities are connected by a throttle has a coefficient of resistance $K_{m}$.

On the basis of the developed equivalent scheme the mathematical model of transport movement of the modular machine-tractor unit which represents system of three differential equations (1) is constructed. In it the following designations are accepted: $M_{t}, J_{t}$ - the mass of the energy module and its moment of inertia with respect to the vertical axis passing through the point $\pi$ (Fig. 2); $k_{a}, k_{b}, k_{c}-$ insertion resistance coefficients of front and rear axle tires of power module and tires of axle wheels of technological module respectively; $J_{m}$ - the moment of inertia of the technological module with the agricultural machine on it, along the axis passing through the point $\pi ; L, a_{m}, b_{m}$ - the constructive parameters of the modular traction device are shown in Fig. 2. 


$$
\begin{aligned}
& \mathrm{A}_{11} \cdot \ddot{X}_{\mathrm{t}}+\mathrm{A}_{12} \cdot \dot{\mathrm{X}}_{\mathrm{t}}+\mathrm{A}_{13} \cdot \dot{\varphi}+\mathrm{A}_{14} \cdot \varphi+\mathrm{A}_{15} \cdot \dot{\beta}+\mathrm{A}_{16} \cdot \beta=\mathrm{B}_{11} \cdot \alpha-\mathrm{R}_{\mathrm{g}}, \\
& \mathrm{A}_{21} \cdot \ddot{\varphi}_{\mathrm{t}}+\mathrm{A}_{22} \cdot \dot{\mathrm{X}}_{\mathrm{t}}+\mathrm{A}_{23} \cdot \dot{\varphi}+\mathrm{A}_{24} \cdot \varphi=\mathrm{B}_{21}, \\
& \mathrm{~A}_{31} \cdot \ddot{\beta}_{\mathrm{t}}+\mathrm{A}_{32} \cdot \dot{\mathrm{X}}_{\mathrm{t}}+\mathrm{A}_{35} \cdot \dot{\beta}+\mathrm{A}_{15} \cdot \beta=\mathrm{M}_{\mathrm{o}}, \\
& \text { where } \mathrm{A}_{11}=\mathrm{M}_{\mathrm{t}}, \mathrm{A}_{12}=\left(\mathrm{k}_{\mathrm{a}}+\mathrm{k}_{\mathrm{b}}+\mathrm{k}_{\mathrm{c}}+\mathrm{P}_{\mathrm{fa}}+\mathrm{P}_{\mathrm{fc}}-\mathrm{F}_{\mathrm{b}}\right) \cdot\left(\mathrm{V}_{\mathrm{o}}\right)^{-1}, \mathrm{~A}_{21}=\mathrm{J}_{\mathrm{t}}, \\
& \mathrm{A}_{13}=\left[\left(\mathrm{L}+\mathrm{a}_{\mathrm{m}}\right) \cdot\left(\mathrm{k}_{\mathrm{a}}+\mathrm{P}_{\mathrm{fa}}\right)+\mathrm{a}_{\mathrm{m}} \cdot\left(\mathrm{k}_{\mathrm{b}}-\mathrm{F}_{\mathrm{b}}\right)\right] \cdot\left(\mathrm{V}_{\mathrm{o}}\right)^{-1}, \mathrm{~A}_{15}=\mathrm{a}_{\mathrm{m}} \cdot\left(\mathrm{k}_{\mathrm{c}}+\mathrm{P}_{\mathrm{fc}}\right), \\
& \mathrm{A}_{14}=-\left(\mathrm{k}_{\mathrm{a}}+\mathrm{k}_{\mathrm{b}}+\mathrm{P}_{\mathrm{fa}}-\mathrm{F}_{\mathrm{b}}\right), \mathrm{A}_{16}=-\left(\mathrm{k}_{\mathrm{c}}+\mathrm{P}_{\mathrm{fc}}\right), \mathrm{A}_{22}=\mathrm{A}_{13}, \quad \mathrm{~A}_{23}=\left[\left(\mathrm{L}+\mathrm{a}_{\mathrm{m}}\right)^{2} \cdot\left(\mathrm{k}_{\mathrm{a}}+\mathrm{P}_{\mathrm{fa}}\right)+\mathrm{a}_{\mathrm{m}}^{2} \cdot\left(\mathrm{k}_{\mathrm{b}}-\mathrm{F}_{\mathrm{b}}\right)\right] \cdot\left(\mathrm{V}_{\mathrm{o}}\right)^{-1}, \\
& \mathrm{~A}_{24}=-\mathrm{A}_{22} \cdot \mathrm{V}_{\mathrm{o}}, \\
& \mathrm{A}_{31}=\mathrm{J}_{\mathrm{m}}, \quad \mathrm{A}_{32}=-\mathrm{A}_{15} \cdot\left(\mathrm{V}_{\mathrm{o}}\right)^{-1}, \mathrm{~A}_{35}=\mathrm{K}_{\mathrm{m}}+\mathrm{A}_{32} \cdot \mathrm{a}_{\mathrm{m}}, \mathrm{B}_{11}=\mathrm{k}_{\mathrm{a}}, \mathrm{B}_{21}=\mathrm{k}_{\mathrm{a}} \cdot\left(\mathrm{L}+\mathrm{a}_{\mathrm{m}}\right), \\
& \mathrm{M}_{\mathrm{o}}=\mathrm{R}_{\mathrm{g}} \cdot \mathrm{b}_{\mathrm{m}}-\mathrm{M}_{\mathrm{m}} .
\end{aligned}
$$

The input variables of the differential equation system (1) are: control effect in the form of angle $\alpha$ of the steering wheels of the power module modular traction unit; disturbing effects in the form of a total turning point $M_{o}=R_{g} \cdot b_{m}-M_{m}$.

The output parameters of the functioning of the considered dynamic system are: displacement $X_{t}$ of the point $\pi$-integrated mass center of a modular traction vehicle; course angle $\varphi$ of the power module; rotation angle $\beta$ of the technological module relative to the energy module.

The motion stability of the considered dynamic system is best carried out with the help of amplitude and phase frequency characteristics. In this case, the amplitude frequency response of a dynamic system is the distribution of the amplification factor by the input frequency of the dynamic system. The phase frequency response of a dynamic system is the distribution in angle or time of its response delay frequency to the input impact.

For dynamic tracking systems (and the one we consider belongs to them) there are ideal amplitude and phase frequency characteristics. In particular, dynamic input disturbance amplification coefficient (i.e. amplitude frequency response) in the whole range of its frequencies must be equal to zero [12]. The delay of the dynamic system response to such an impact should be as large as possible, ideally it should strive for infinity [12].

At such approach the essence of mathematical modelling of movement stability of this or that dynamic system is reduced to selection of such its parameters which provide the greatest approximation of real amplitude frequency characteristic and phase frequency characteristic to ideal.

Valid amplitude and phase frequency characteristics are obtained from the corresponding transfer functions. In our case, the transfer function is at the turning moment $M_{\circ}$ about the course angle $\varphi$ of the energy module looks like:

$$
W_{1}=\frac{b_{6} \cdot p+b_{5}}{a_{6} \cdot p^{4}+a_{5} \cdot p^{3}+a_{4} \cdot p^{2}+a_{3} \cdot p+a_{2}} .
$$

The same function for the same disturbing influence, (i.e. the moment $M_{\circ}$ ), but about the angle $\beta$ of the rotation of the technology module is more complex:

$$
W_{2}=\frac{b_{4} \cdot p^{3}+b_{3} \cdot p^{2}+b_{2} \cdot p+b_{1}}{a_{6} \cdot p^{4}+a_{5} \cdot p^{3}+a_{4} \cdot p^{2}+a_{3} \cdot p+a_{2}} .
$$

Equations (2) and (3) take the following notation:

$$
\begin{aligned}
b_{6} & =A_{15} A_{22}, b_{5}=A_{16} A_{22}, b_{4}=A_{11} A_{21}, b_{3}=A_{12} A_{21}+A_{11} A_{23}, b_{2}=A_{11} A_{24}+A_{12} A_{23}-A_{13} A_{22}, \\
b_{1} & =A_{12} A_{24}-A_{22} A_{14}, a_{6}=A_{11} A_{21} A_{31}, \\
a_{5} & =A_{12} A_{21} A_{31}+A_{11} A_{31} A_{23}+A_{11} A_{21} A_{35}, \\
a_{4} & =A_{11} A_{31} A_{24}+A_{12} A_{23} A_{31}-A_{13} A_{22} A_{31}+A_{11} A_{21} A_{36}+A_{12} A_{21} A_{35}- \\
& -A_{21} A_{32} A_{15}+A_{11} A_{23} A_{35}, \\
a_{3} & =A_{12} A_{31} A_{24}-A_{22} A_{31} A_{14}+A_{12} A_{21} A_{36}+A_{11} A_{23} A_{36}-A_{21} A_{32} A_{16}+ \\
& +A_{11} A_{24} A_{35}+A_{12} A_{23} A_{35}-A_{13} A_{22} A_{35}-A_{12} A_{31} A_{24}, \\
a_{2} & =A_{11} A_{24} A_{36}+A_{12} A_{23} A_{36}+A_{12} A_{24} A_{35}-A_{13} A_{22} A_{36}-A_{22} A_{14} A_{35}- \\
& -A_{23} A_{14} A_{35}-A_{23} A_{32} A_{16}-A_{32} A_{15} A_{24} .
\end{aligned}
$$


In the course of experimental studies, the soil moisture of the agrotechnical background in the layer 0 $\ldots 10 \mathrm{~cm}$ did not exceed $14.5 \%$. The modular plow truck was moving at a speed of $3,95 \mathrm{~m} \cdot \mathrm{s}^{-1}$. This value of speed $V_{\circ}$ motion was used to calculate the transfer function (3) of the theoretical $\left(A_{t}\right)$ of the amplitude frequency response of the studied machine-tractor unit of the disturbing effect (moment $M_{0}$ ). Comparison of this characteristic with the experimental one $\left(A_{e}\right)$ indicated their satisfactory convergence (Fig. 3).

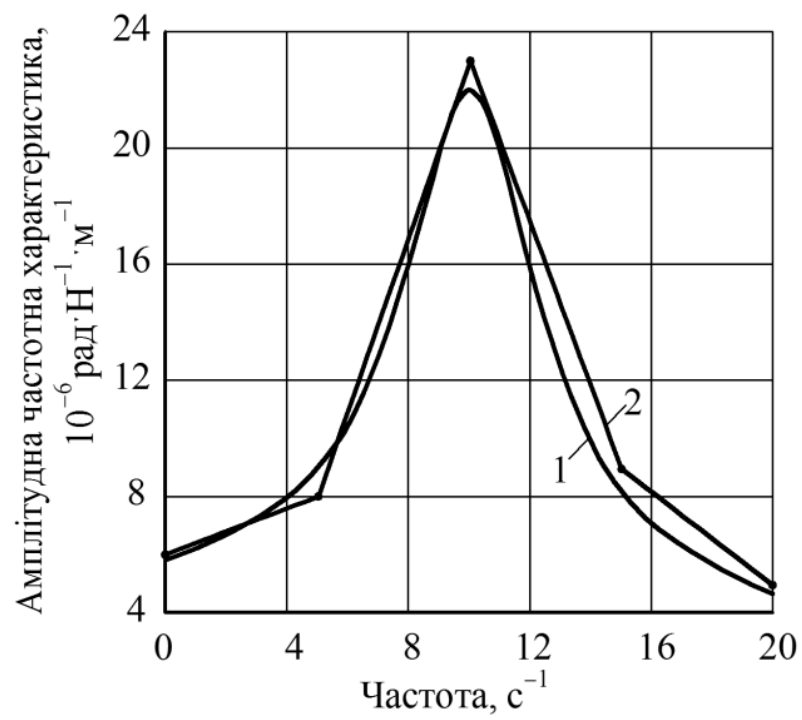

Fig. 3. Amplitude frequency characteristics of the unit: 1 - theoretical $A_{t,} ; 2$-experimental $A_{e}$

And it definitely indicates that the mathematical model (1) of the transport movement of the modular traction device with the agricultural machine (in this case - the plough) is adequate, and therefore fully suitable for further theoretical studies.

The theoretical analysis of the obtained amplitude and phase frequency characteristics, based on the use of the transfer function (3), has shown that with increasing the speed of the investigated unit from 2 to $5 \mathrm{~m} \cdot \mathrm{s}^{-1}$ the amplitude frequency response of the rotation angle $\beta$ of the technological module when working out their disturbing influence (moment $M_{\circ}$ ) have a resonant peak at a frequency of $10 \mathrm{~s}^{-1}$ (Fig. 4).

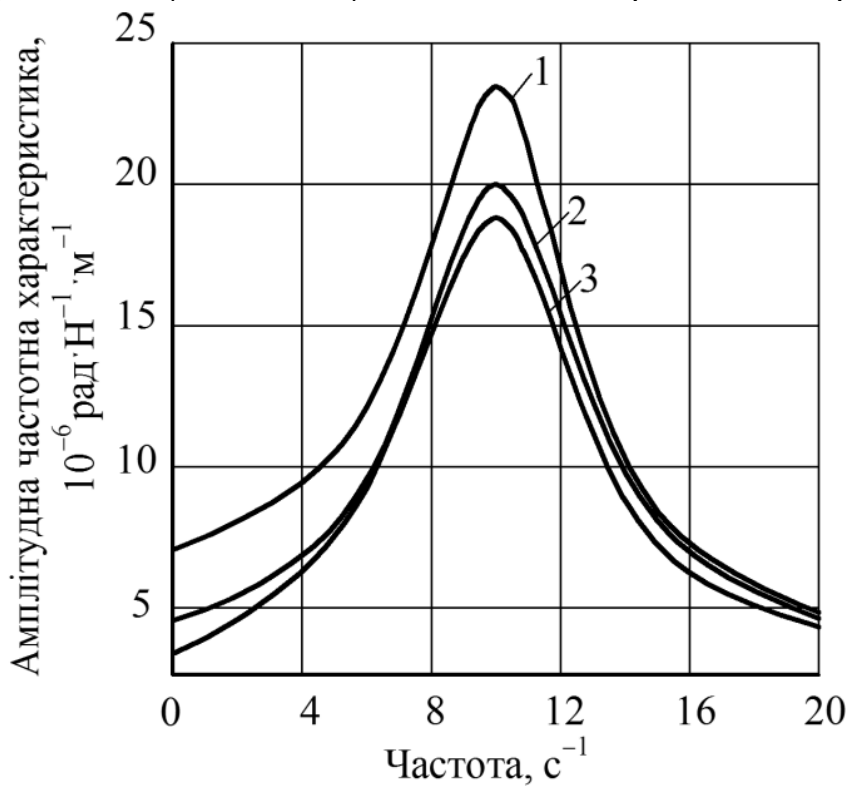

Fig. 4. The amplitude frequency response of the angle $\beta$ when working out the technological module of the disturbing influence at different speed of movement of the modular unit $\left(V_{0}\right): 1$ $2 m \cdot s^{-1} ; 2-3 m \cdot s^{-1} ; 3-5 m \cdot s^{-1}$

The amplitude frequency characteristics themselves change very little. Especially at speed $V_{0}=2 \mathrm{~m} \cdot \mathrm{s}^{-}$ 1 and more. This fact can be explained by the inertia of the technological module with a plough aimed at it, which manifests itself more effectively with increasing speed of the unit. 
As for the phase frequency response, in the frequency range $0 \ldots 10 \mathrm{~s}^{-1}$ they differ a little (Fig. 5).

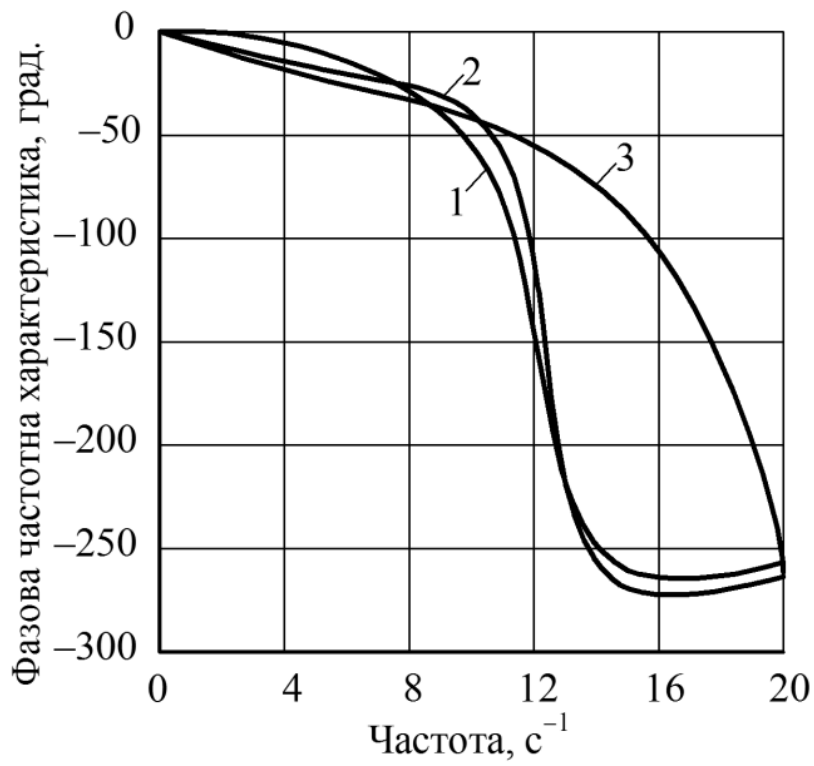

Fig. 5. Phase frequency response of the angle $\beta$ when working out technological module of disturbing influence at different speed of movement of the modular unit $\left(V_{0}\right): 1-2 \mathrm{~m} \cdot \mathrm{s}^{-1} ; 2-3$ $m \cdot s^{-1} ; 3-5 m \cdot s^{-1}$

A significant difference in the delay of the reaction of the technological module to the disturbing effect appears at frequencies of $10 \ldots 20 \mathrm{~s}^{-1}$, and then it disappears again. As can be seen from the graph (Fig. 5 ), this difference is maximal at a frequency of approximately equal to $15 \mathrm{~s}^{-1}$. It is $200^{\circ}$ or $3,5 \mathrm{rad}$. So, with increasing speed from 2 to $5 \mathrm{~m} \cdot \mathrm{s}^{-1}$ the delay of the technological module reaction to the disturbing effect will be reduced by only $3,5 \cdot 15^{-1}=0.23 \mathrm{~s}$. At other frequencies this difference is even smaller. Therefore, the transport speed of movement of this modular traction unit when it is changed from 2 to $5 \mathrm{~m} \cdot \mathrm{s}^{-1}$ has very little effect on the process of oscillation of the rotation angle of the technological module during the action of disturbing effects in the form of turning moment.

\section{Conclusions}

Developed mathematical model of transport movement of the unit based on the modular traction vehicle is adequate. The research results obtained on the basis of its use show the following:

- change of movement speed of the unit from 2 to $5 \mathrm{~m} \cdot \mathrm{s}^{-1}$ does not lead to deterioration of stability of movement of neither technological nor, moreover, energy modules of modular traction device. Amplitude frequency response of the working out by them disturbing turning moment with increasing parameter $V_{o}$ even if it is not much, but it is improving. Phase frequency response of the technological module of the modular traction device of this moment slightly deteriorates, but only at relatively high frequencies of its oscillation - more than $10 \mathrm{~s}^{-1}$. Reaction delay of the energy module of the modular traction device is practically invariant with respect to changes in the mode of movement of the unit in the range of $2 \ldots 5 \mathrm{~m}$ $\cdot \mathrm{S}^{-1}$;

- the values of the input resistance coefficients of the wheels of the energy module do not create any significant influence on the development of the disturbing moment oscillations. At the same time, the value of the input resistance coefficient of each wheel of the technological module of the modular traction vehicle must be at least $160 \mathrm{kN} \cdot \mathrm{rad}^{-1}$.

\section{References}

1. Anche, M., \& Subramanian, C. (2018). Model based compensator design for pitch plane stability of a farm tractor with implement. IFAC-PapersOnLine 51, 208-213. doi: 10.1016/j.ifacol.2018.05.043.

2. Bulgakov, V., Kurchev, V., Nadykto, V., \& Olt, J. (2015). Structure development and testing results of a new modular power supply unit. Elsevier Srl. Agriculture and Agricultural Science Procedia, 7, 40-44. doi: 10.1016/j.aaspro.2015.12.028.

3. Bulgakov, V., Parakhin, O., Mitkov, V., \& Chorna, T. (2019). The coefficient determination of a damper washer hydraulic resistance for reducing a technical module oscillation amplitude. Modern Development Paths of Agricultural Production, 3, 183-190. doi: 10.1007/978-3-030-14918-5_20.

4. Demsar, I., Bernik, R., \& Dukhovnik, D. (2012). Matematicheskaya model $i$ chislennoye modelirovaniye staticheskoy ustoychivosti traktora [Mathematical model and numerical modeling of static stability of a tractor]. Agric. Conspec. Sci., 77, 143-150. [In Russian]. 
5. Moradi, N., \& Ghasemi, A. (2018). A new current controller design for tractor active suspension using by model order reduction. Applied Science Reports, 23-30. doi: 10.15192/PSCP. ASR.2018.23.1.2330.

6. Hac, A., Fulk, D., \& Chen, H. (2008). Stability and control considerations of vehicle-trailer combination. SAE Int. J. Passeng. Cars - Mech. Syst. 1, 925-937. doi: 10.4271/2008-01-1228.

7. Kutkov, G. M. (2004). Traktory $i$ avtomobili. Teoriya $i$ tekhnologicheskiye svoystva [Tractors and cars. Theory and technological properties]. Moscow: Kolos. [In Russian].

8. Li, Z., Mitsuoka, M., Inoue, E., Okayasu, T., Hirai, Y., \& Zhu, Z. (2016). Parameter sensitivity for tractor lateral stability against Phase I overturn on random road surfaces. Biosyst. Eng., 150, 10-23. doi: 10.1016/j.biosystemseng.2016.07.004.

9. Macmillan, R. H. (2002). The mechanics of tractor - implement performance. University of Melbourne.

10. Nadykto, V., Karaev, O., Kurchev, V., \& Beloev, H. (2019). Efficiency of using a tractor with a hinged-articulated frame for crop cultivation. In: Nadykto V. (Ed.). Modern ways of development Agricultural production. Springer International Publishing, Cham. (pp. 161-167). doi: 10.1007/978-3-03014918-5_17.

11.Pascuzzi, S. (2015). A multibody approach applied to the study of driver injuries due to a narrowtrack wheeled tractor rollover. J. Agric. Eng., 46, 105-114. doi: 10.4081/jae.2015.466.

12.Rotach, V. Yu. (2008). Teoriya avtomaticheskogo upravleniya [Automatic control theory]. Moscow. [In Russian].

13.Song, P., Zong C., \& Tomizuka M. (2014). A terminal sliding mode based torque distribution control for an individual-wheel-drive vehicle. J. Zhejiang Univ. Sci., 15, 681-693. doi: 10.1631/jzus. A1400101.

14. Szakacs, T. (2010). Developing stability control theories for agricultural transport systems. Acta Polytech. Hungarica, 7, 25-37.

15. Xie, L. (1984). Simulation of tractor-trailer system stability. SAE Tech. Pap. lowa State University. doi: $10.4271 / 851530$.

16. Yildiz, S. (2010). Improving high speed lateral stability of longer and heavier vehicles by active steering. Master's Thesis. Eindhoven. 